\title{
Banking Sector Growth in China: Can Six-Sigma Be a Solution?
}

\author{
Lixia Wang \\ PhD Candidate, School of Management, Shanghai University, PR China \\ E-mail: lilywlx6@gmail.com \\ Iftikhar Hussain (Corresponding author) \\ $\mathrm{PhD}$ Candidate, School of Management, Shanghai University, PR China \\ E-mail: iftikhar_raja@live.com
}

\begin{abstract}
Banking industry in China is facing immense competition from local as well as foreign banks, customers choices regarding banks are expanding. At present, banking is increasingly becoming a consumer-centric service provider. Customers are becoming more quality conscious and are demanding new and qualitative products and services. Six Sigma is a kind of quality enhancement strategy that can help a bank to win customers' loyalty. However, Six Sigma alone is not enough to meet the rapidly increasing competition, an alignment between Six Sigma and knowledge management is essential. The study examines the gainful effects of the use of knowledge management and also gives a critical analysis of the impact of six-sigma on banking performance and customer services. The study examined that quality assurance practice, like Six Sigma along with knowledge management can be an effective strategy for banking sector in China. Finally, the study proposed a model for banking sector to ensure high quality products and services.
\end{abstract}

Keywords: Six Sigma, Knowledge management, Quality, Banks, China

\section{Introduction}

The current challenging economic environment has placed considerable stress on financial institutions to decrease costs and sustain a greater level of clients' satisfaction. Particularly US based recent financial crisis put even more pressure on banks and other financial institutions to increase the quality of their products and services and built more customer satisfaction to achieve high customer loyalty. Such quality issues can be better dealt with quality improvement techniques, particularly Six Sigma. As Kumar, Wolfe and Wolfe (2008) indicated that Six Sigma has the potential to produce better results in financial sector.

Financial institutions in present competitive environment need to be innovative as well as build quality products and services. Like manufacturing sector, improving quality has also become a serious consideration in banking sector. As quality improvement is an effective approach in attracting and retaining customers. Quality improvements programs like total quality management (TQM), Six Sigma, reengineering, bench marking are employed by different organizations (Hoerl and Snee, 2002). However, Six Sigma is relatively effective to services due to its customer-driven focus (Tagahaboni and Moreland, 2004). Also, Six Sigma is an effective strategy to improve business performance through minimizing inaccuracies and inconsistencies.

Banking industry in China is facing immense competition from local as well as foreign banks, customers choices regarding banks are expanding. Customers are becoming more quality conscious and are demanding new and qualitative products and services. Six Sigma is a kind of quality enhancement strategy that can help a bank to win customers' loyalty. However, Six Sigma alone is not enough to meet the rapidly increasing competition, an alignment between Six Sigma and knowledge management is necessary. The study examines the gainful effects of the use of knowledge management and also gives a critical analysis of the impact of Six Sigma on banking performance and customer services. The study examined that quality assurance practice, like Six Sigma along with knowledge management can be an effective strategy for banking sector in China. Finally, the study proposed a model for banking sector to ensure high quality products and services.

The adoption of Six Sigma in an organization is not a certification of success; in fact its true implementation is essential. The true implementation of six-sigma must possess adequate merits. The remainder of the study discusses the important aspects of Six Sigma, advantages as well as factor influencing effective implementation of Six Sigma. Mainly, the relevance of Six Sigma to organizational knowledge management efforts is discussed. Further, the study proposed a Six Sigma and knowledge management alignment model for banking sector in China. 
Finally the study concludes and provides future lines of research.

\section{Six Sigma}

According to Lin et al. (2009) Six Sigma was initiated by Motorola in the 1980s. Hayler and Nichols (2006) defined Six Sigma as "use of facts and data to reduce process variations, thereby enabling organizations to deliver consistent, high quality services to customers." The two key methodologies used in Six Sigma are DMAIC and DMADV. DMAIC stands for define, measure, analyze, improve, and control. In the define phase organizations defines the problems, key process characteristics are identified, studied and benchmarked in the measure and analyze phases. In the improve phase solutions are created and implemented for a better or optimized performance. The control phase then ensures that the problem does not appear again. In banking sector mostly, DMAIC is used because banks usually adopted Six Sigma to improve processes not creates new ones.

Harry and Schroeder (1999) defined Six Sigma as 'a disciplined method of using extremely rigorous data gathering and statistical analysis to pinpoint sources of errors and ways of eliminating them'. However, according to Antony and Banuelas (2002) Six Sigma employ statistical and non-statistical tools and techniques to minimize process variation and enhance process performance and competence. Linderman et al. (2003) also considers the importance of statistical as well as non-statistical tools and defined Six Sigma as: 'Six Sigma is an organized and systematic method for strategic process improvement and new product and service development that relies on statistical methods and the scientific method to make dramatic reductions in customer defined defect rates'. However, as (Antony and Banuelas, 2001) described in business world the term Six Sigma is defined differently, "Six Sigma is business strategy used to improve business profitability, to improve the effectiveness and efficiency of all operations to meet customers' needs and expectations." In views of Hahn et al. (2000) Six Sigma is a product and process quality enhancement approach based on statistical tools and discipline. Other researchers take Six Sigma as a management strategy requiring cultural changes (Sanders and Hild, 2000). Schroeder et al. (2008), after a detail study of literature and consulting many practitioners defined Six Sigma as "Six Sigma is an organized, parallel-meso structure to reduce variation in organizational processes by using improvement specialists, a structured method, and performance metrics with the aim of achieving strategic objectives."

Many studies have discussed the meanings, concepts and value of Six Sigma in today's competitive business environment (Brady \& Allen, 2006; Folaron, 2003; Nonthaleerak \& Hendry, 2006). Six Sigma applications involve more customer focused approach. As (Goh, 2002) identified that in comparison with other quality assurance strategies like of ISO or QS, Six Sigma is a lot more receptive to client satisfaction.

\subsection{Six Sigma Significance in Banking Industry}

Several studies have conferred the advantages of employing Six Sigma (Hahn et al., 1999; Hendricks and Kelbaugh, 1998; Lanyon, 2003; Robinson, 2005). These studies identified different benefits like improving the market share and building competitive advantage for a business. Quality enhancement in banking sector requires investigating the needs and desires of diverse stakeholders (like, clients, share-holders, employees). The quality enhancement efforts also need to ensure effective implementation of quality ensuring programs through statistical tools. There are number of aspects which, creates the need for quality improvement solutions like Six Sigma in banking industry in China. Clients' desires for high quality products and services, greater competition for expanding consumers' base, revolution in international financial markets, and requirements of continuously changing global business situations.

Kwak and Anbari (2006) described several benefits of Six Sigma in their study, which includes; improved the net profits, improved HR processes, reduction in wastes, reduced failure rates, improved savings through cost reductions and reduction of packaging defects. Six Sigma is an effective quality management tool and yields multiple benefits (Dusharme, 2006). Banking sector in China can employ Six Sigma in their operations to provide quality services to their customers. Investing in Six Sigma will not only improve the quality of their products and services, this will also provide them with opportunity to earn more profits through attracting new customers. As Anon (2003) concluded that Six Sigma is a highly payable quality strategy. He further described that Six Sigma returns are more than twice of their investment. On the other hand Doran (2003) illustrated several advantages of Six Sigma particularly for banking industry. These advantages includes ensuring accuracies in distribution of cash to reduce service charges, ensuring accuracies in daily reports through an effective information system, minimizing number of defects in loans provision processes, reducing number of defects in cheque payments and collections and decreasing inefficiencies in routine operations.

The application of Six Sigma in bank also helps managers to tackle such issues as i) recording and reducing customer grievances, ii) recording and minimizing the time needed to complete a particular transaction, iii) measuring, analyzing and ensuring effective provision of services, and iv) minimizing errors in different 
transactions.

\section{Factors to Be Considered in Successful Implementation of Six Sigma in Banks}

Six Sigma methods have been effectively employed by some organizations in previous years to develop service provision and consumer satisfaction. Also, today many organizations are adopting Six Sigma to solve their quality related issues. However, all these organizations are not able to get its total benefits. Perhaps this is due to poor implementation strategy adopted by several organizations. Particularly the banking sector in China in order to get maximum benefits through Six Sigma needs to care about following factors during its implementation. These factors can increase the chances of achieving Six Sigma implementation goals in China's banks.

\subsection{Supportive Organizational Culture}

The successful adoption of Six Sigma needs a supportive organizational culture. The organizations need to embed Six Sigma in their culture. This needs sincerity form management of an organization as well as employees. Particularly it requires sincere efforts from top management. As top management commitment is described as the most important factor of Six Sigma success (James and Allem, 2006). Hence, top management full commitment and loyalty is essential for Six Sigma successful implementation. Several studies in literature have identified management commitment as significant contributor to the effective implementation of Six Sigma (Antony and Banuelas, 2002; Banuelas Coronado and Antony, 2002: Henderson and Evans, 2000; Johnson and Swisher, 2003).

\subsection{Training and Development}

Another key factor to be considered for successful Six Sigma implementation is proper training of managers and employees engaged in Six Sigma implementation. As Aravind et al. (2007) described, in order to ensure that employees at all levels are familiar with and had access to quality process management methods, terminologies, techniques and resources, all employees engaged in Six Sigma programs must attain certain level of training.

Some other studies have also discussed the significance of training and development in Six Sigma success (Hahn \& Doganaksoy, 2008; Hahn et al., 1999; Snee, 1999). The adoption of Six Sigma methodologies without required skills in employees is inadequate. Employees must acquire required skills through training before joining Six Sigma implementation projects. As described in literature training and knowledge about statistical and non-statistical tool usage is important for Six Sigma implementation (Hahn et al., 2001; Lee, 2002; Snee, 2000)

\subsection{Avoid Short-Centered Approach}

Another issue in Six Sigma implementation is that some organizations adopt short centered approaches. Such approaches are adopted to reach end results earlier. However, the adoption of such approaches leads ineffective results. The organizations need to focus all the stages of Six Sigma uniformly. The lack of commitment from organization at any stage can lead ineffective implementation of Six Sigma. Like during the problem identification stage the organization may refer some factors as cause of a particular problem without analyzing data. This kind of an approach may lead serious problems in gaining benefits out of Six Sigma strategy.

\subsection{Excessive Concentration on Costs Reduction}

Most of the organizations and particularly banks try to concentrate more on reducing costs of their operations and services. However, this is not effective in Six Sigma implementation. The banks need to focus more on improving their organizational output. Banks should train their employees and try to minimize the time spent on different transactions and provision of services. This will also help banks in minimizing the overall time required for Six Sigma strategy implementation and gaining quality improvements objectives.

\subsection{A Continuously Learned Process}

Maintaining high quality standards through Six Sigma is a continuous process. The employees working in an organization continue to understand and nurture through the use of the process improvement tools. The top management involved in the process first learns and then leverage their skills to other levels in order to support other employees involved in this continuous journey. The global competition in banking and other services is creating several kinds of challenges for quality improvement managers. These novel challenges provide employees involved in quality assurance programs with yet better chances for learning and taking part to personal and organizational growth and development. Therefore, organizations need to take Six Sigma as a continuously learning process in order to meet the newly arising challenges in business arena.

\section{Six Sigma Developments in Banking Sector}

Citibank was the first in banking industry who implemented Six Sigma strategy to meet customers' requirements and attain client's satisfaction and reliability (Rochelle, 2000). Bank of America is also one of the leading adopter 
of Six Sigma and has experienced significant impact on bank's performance and reducing defect rates (Daniel and James, 2005; Roberts, 2004).

China Construction Bank (CCB) is the first one in Chinese banking industry, to start Six Sigma implementation to improve effectiveness of its operations. The CCB decided to employ Six Sigma in 2006 and started its' employees training with the help of Six Sigma professionals. Hence, CCB realized the need and significance of implementing Six Sigma to improve its services and achieve higher customers' satisfaction rates. Before implementing Six Sigma, CCB was relying largely on usual methods of banking operations. The CCB intends to develop a quality control system based upon statistical and non-statistical tools rather than traditional experience practices. Other banks employed six sigma include Merchants Bank, Minsheng Bank, Industrial Bank, Shanghai Pudong Development Bank (SBTI, 2009). However, still Six Sigma is in infant stage in China.

\subsection{Six Sigma Strategies in Banking Sector}

After its' development in 1980's Six Sigma was largely employed by the manufacturing sector to reduce usual defects. However, with the evolution of new methods and tools Six Sigma is also being employed in service sector, specifically in banking sector. The Six Sigma strategy mostly employed in banking sector is DMAIC. The detailed discussion of DMAIC elements is as follow.

\subsection{Define}

The 'define' is the first phase of Six Sigma process. During this phase Six Sigma teams, managers and other staff members coordinately define the aims and limits of specific banking processes. Clients' satisfaction is considered as central aim of Six Sigma in banking industry, therefore in this stage all those processes are defined which include consumers' connections and directly or indirectly influence clients' satisfaction. Purchasing new banking products and services like saving certificates, requesting changes in existing accounts, opening new accounts and requesting ATM cards are the examples of such processes.

\subsection{Measure}

The second phase involves implementation of different quantitative methods and tools to gather required statistical information. The Six Sigma teams after collecting necessary data with the cooperation of senior managers use this data to measure the affect of different banking practices and processes on clients' satisfaction. The affect of various banking practices and processes varies from each other. The effective measurement of influence of different practices and processes assist the banks to improve the quality of specific measured practices and processes. It is not necessary that every practice or process will have financial impacts. However, non-financial impact is also important. In today's competitive environment time is the most scare resource; therefore saving customers' time is regarded critical for clients' satisfaction. The banks' employing Six Sigma observes and measure average time taken in dealing with an individual customer or for a specific transaction.

\subsection{Analyze}

During this stage of Six Sigma implementation analysis of the gathered data is conducted according to the measures used and priorly defined standards with the purpose of highlighting the practices and processes which could be better developed at a lower cost. The analyze phase involves various aspects of banking processes which can put certain impacts on clients' satisfaction. The examples of such processes can be a cheque presentation and cash receiving time, a bill collection time, a demand draft request and preparation time. Such processes are analyzed regarding how much time they take and what are their impacts on business performance and service quality.

\subsection{Improve}

During this stage of DMAIC process, the managers and professionals engaged in Six Sigma implementation employ several actions to improve practices and process which results different sort of problems in daily banking operations. The corrective actions and measures taken are based on data collected during measure phase and analyzed during analyze phase. The professionals and managers engaged in Six Sigma implementation can use other advanced statistical and non-statistical tools to investigate the impacts of quality enhancement measures taken on different banking practices and processes.

\subsection{Control}

During 'control' stage of DMAIC process, specified controlling system are employed in banking operations to measure the influence of actions taken for quality enhancement. In case, the banking practices and processes are not improved as per defined Six Sigma levels, even after, the actions taken. The DMAIC process will again start from 'define' stage. On the other hand, if the problem causing ineffective Six Sigma performance is of a minor 
nature, in that case corrective actions are employed and the complete process is not repeated.

\section{Knowledge Management}

Oakland (1989) described quality as blend of systems, tools and people. The three elements of quality improvement described in his study emphasized the development of an effective organizational quality improvement system, selection of appropriate statistical and non-statistical tools and finally an effective work force. The third element of his definition is mainly concerned with employees' development. Knowledge Management can play an important role in employees' development. The implementation of knowledge management strategy will enhance individual knowledge management capabilities as well as organizational. Employees' knowledge management capabilities' development will indirectly also affect other two elements of his definition.

The two important considerations expressed in literature regarding people element are; organizational culture and leadership and training (Hahn et al., 1999; Hoerl, 2001; Sanders and Hild, 2000; Wiklund and Wiklund, 2002). Knowledge management through an effective strategy can help an organization developing a supportive organizational culture as well as developing leadership and workers capabilities through knowledge sharing. Further, creating new knowledge will improve organizational processes as well as organizational productivity and provide organizations with better competitive position (Shah and Ward, 2003; Zu et al., 2008).

\section{Six Sigma and Knowledge Management Alignment}

James and Allem (2006) described two main principles of Six Sigma strategy. Both these principles emphasized the need of knowledge capability development of employees working in an organization. They emphasized the employees' capability development regarding statistical and other tools used in Six Sigma strategy, through training and other sources. The attainment of quality goals through Six Sigma strategy largely depends upon employees' capabilities to successfully utilize statistical and non-statistical tools and procedures. Therefore developing employees' capabilities through an effective knowledge management strategy is essential to achieve quality goals in an organization. Employees, particularly leaders in an organization are trained so that they can collect, combine and synthesize organizational and individuals' knowledge for better process management and quality improvements (Hoerl, 2001). Employees contain tacit as well as explicit knowledge. Quality improvement strategies need to use these two kinds of knowledge, specifically tacit knowledge. Employees' knowledge capabilities through knowledge creation and utilization can help organizations in achieving quality improvement objectives through introducing new products and services and improving quality through incorporation of new features in existing products.

Anand et al. (2010) empirically tested relationship between knowledge management practices and Six Sigma projects success using data collected from U.S. companies deploying Six Sigma initiatives. He found knowledge management as a vital element of Six Sigma strategy.

Managers in banking sector deals with diverse kind of problems. Most of these problems relate to clients' dissatisfaction and ineffective operations management. In order to deal these problems successfully managers' usually adopt DMAIC approach. The ineffectiveness of operations affect more the quality aspect of banking services and leads customers' dissatisfaction. In order to manage these two main problems effectively a mixture of both DMAIC and knowledge management approaches is proposed in this study. The DMAIC approach ensures quality improvements and reduces cost of products and services as indicated in figure 1. Such quality improvements and decrease in costs provide more value to clients and leads customer satisfaction. Alternately customer satisfaction generates more profits and satisfaction for businesses or banks shareholders.

On the other hand the knowledge management approach ensures introduction of new products and services through improved employees capabilities, which enhances customer satisfaction through availability of new and additional features in products and services provided by banks. The availability of new products and services with additional features to clients of a bank lead more value and satisfaction to it's customers. As a result banks get more investment form existing clients as well as new clients, which enhance bank's profits. The study suggested this model due to its' dual effect on bank's profit and clients' satisfaction. Achieving profits and clients' satisfaction goals at the same time will facilitate bankers to improve their performance.

Insert figure 1 here 


\section{Conclusion}

The study concludes that methods, tools and techniques of Six Sigma strategy have greater impact on quality improvements and performance in various industries. Although, the experience of Six Sigma in banking sector is relatively new, however, its impact over banking performance is significant. Many banks have attained greater performance goals after implementing Six Sigma (Daniel and James, 2005; Roberts, 2004).

This study enlightened the concept of Six Sigma through its' various definitions and highlighted the importance of Six Sigma in general and particularly in banking sector. The study also reviewed the implementation of Six Sigma in banking sector and discussed various factors which affect the successful implementation of Six Sigma in banking industry. The study concludes that the DMAIC model used in banking sector for quality improvements is fine. However, DMAIC model alignment with knowledge management can produce better results in banking industry. Applying knowledge management along with Six Sigma tools plays an important role in enhancing the quality of operations in banks.

Due to the time and financial constraints this study didn't empirically tested the implementation of Six Sigma in banking sector in China. However, the future researchers can empirically assess the implementation of Six Sigma using the proposed model.

\section{References}

Anand, G., Peter, T. W., and Mohan V. T. (2010). Role of explicit and tacit knowledge in Six Sigma projects: An empirical examination of differential project success. Journal of Operations Management, 28 (4), 303-315.

Anon. (2003). Revealing study of Six Sigma: gains but missed opportunities. Strategic Direction, 19 (8), 34-36.

Antony, J., and Banuelas R. (2002). Key ingredients for the effective implementation of Six Sigma program. Measuring Business Excellence, 6(4), 20-27.

Antony, J., and Banuelas, R. (2001). Six Sigma: A Business Strategy for Manufacturing Organizations. Manufacturing Engineering, 8(3), 119-121.

Aravind, I., Allen, M., Gus, C., and Ron A. (2007). Capital One Banks on Six Sigma for Strategy Execution and Culture Transformation. Global Business and Organizational Excellence, 26(6), 43-54. DOI: 10.1002/joe.20173.

Banuelas Coronado, R., and Antony, J. (2002). Critical success factors for the successful implementation of Six Sigma projects in organizations. The TQM Magazine, 14 (2), 92-99.

Brady, J.E., and Allen, T.T. (2006). Six Sigma literature: A review and agenda for future research. Qual. Reliab. Eng. Int., 22(3), 335-367.

Daniel, Cox and James, Bossert. (2005). Driving Organic Growth at Bank of America. Quality Progress, pp. 23-27.

Doran, C. (2003). Using Six Sigma in the credit department. Credit Management, Dec, 32-34.

Dusharme, D. (2006). Six Sigma Survey: Big Successy What About Other 98 Percent? Quality Digest, [Online] Available: /http://www.qualitydigest.com/ feb03/articles/01_article.shtmlS. (25th May 2010)

Folaron, J. (2003). The Evolution of Six Sigma. Six Sigma Forum Magazine, 2(4), 38-44.

Goh TN. (2002). A strategic assessment of Six Sigma. Quality and Reliability Engineering International, 18(5), 403-410.

Hahn, G., Doganaksoy, N., and Stanard, C. (2001). Statistical tools for Six Sigma-what to emphasize and de-emphasize in training. Quality Progress, 34(9), 78-82.

Hahn, G., Hill, W., Hoerl, R., and Zinkgraf, S. (1999). The impact of Six Sigma Improvement-a glimpse into the future of statistics. The American Statistician, 53(3), 208-215.

Hahn, G.J., and Doganaksoy, N. (2008). The Role of Statistics in Business and Industry. Hoboken, NJ: Wiley.

Hahn, G.J., Doganaksoy, N., and Hoerl, R. (2000). The evolution of Six Sigma. Quality Engineering, 12 (3), 317-326.

Harry, M.J., and Schroeder, R. (1999). Six Sigma: The Breakthrough Management Strategy Revolutionizing the World's Top Corporations. Doubleday: New York.

Hayler, R., and Nichols, M. (2006). Six Sigma for Financial Services: How Leading Companies are Driving Results Using Lean, Six Sigma and Process Management. (1 ed.). New York: McGraw Hill.

Henderson, K.M., and Evans, J.R. (2000). Successful implementation of Six Sigma: benchmarking general electric 
company benchmarking. An International Journal, 7 (4), 260-281.

Hendricks, C.A., and Kelbaugh, R.L. (1998). Implementing Six Sigma at GE. The Journal of Quality and Participation, 21 (4), 43-48.

Hoerl, R., and Snee, R.D. (2002). Statistical Thinking: Improving Business Performance. Duxbury Press, Pacific Grove, CA.

Hoerl, R.W. (2001). Six Sigma black belts: what do they need to know? Journal of Quality Technology, 33 (4), 391-406.

James, E. Brady and Allen, T. T. (2006). Six Sigma Literature: A Review and Agenda for Future Research. Qual. Reliab. Engng. Int. 22:335-367

Johnson, A., and Swisher, B. (2003). How Six Sigma improves R\&D. Research Technology Management, 46 (2), $12-15$.

Kumar, S., Wolfe, A.D., and Wolfe, K.A. (2008). Using Six Sigma DMAIC to improve credit initiation process in a financial services operations. International Journal of Productivity and Performance Management, 57(8), 659-676.

Kwak, Y.H., and Anbari, F.T. (2006). Benefits, obstacles and future of Six Sigma. Technovation: The International Journal of Technological Innovation, Entrepreneurship and Technology Management, 26 (5-6), 708-715.

Lanyon, S. (2003). At Raytheon Six Sigma works, too, to Improve HR management processes. Journal of Organizational Excellence, 22 (4), 29-42.

Lee, K. (2002). Critical success factors of Six Sigma implementation and the impact on operations performance. Ph.D. Dissertation, Cleveland State University.

Lin, C. T., Lee, C., \& Wu, C. S. (2009). Optimizing a marketing expert decision process for the private hotel. Expert Systems with Applications, 36, 5613-5619.

Linderman, K., Schroeder, R. G., Zaheer, S, and Choo, A.S. (2003). Six Sigma: A goal-theoretic perspective. Journal of Operations Management, 21:193-203.

Nonthaleerak, P., \& Hendry, L.C. (2006). Six Sigma: Literature review and key future research areas. Int. J. Six Sigma Competitive Advantage, 2(2), 105-161.

Oakland, J. (1989). Total Quality Management. Butterworth-Heinemann: London.

Roberts, C.M. (2004). Six Sigma signals. Credit Union Magazine, 70 (1), 40-43.

Robinson, B. (2005). Build a management system based on Six Sigma. ASQ Six Sigma Forum Magazine, 5 (1), 28-34.

Rochelle, R. (2000). Citibank Increases Customer Loyalty with Defect-Free Processes. The Journal for Quality and Participation, pp. 32-36.

Sanders, D., and Hild C. (2000). Six Sigma on business processes: Common organizational issues. Quality Engineering, 12(4), 603-610.

SBTI. (2009). Six Sigma in China, [Online] Available: http://www.sbtionline.com.cn/Consult_finance13.aspx, (15 June, 2010).

Schroeder, R., Linderman, K., Liedtk, C., and Choo, S. A. (2008). Six Sigma: Definition and underlying theory. Journal of Operations Management, 26 (4), 536-554.

Shah, R., and Ward, P.T. (2003). Lean manufacturing: context, practice bundles, and performance. Journal of Operations Management, 21 (2), 129-149.

Snee, R. (2000). Six Sigma improves both statistical training and processes. Quality Progress, 33(10), 68-72.

Snee, R.D. (1999). Why Should Statisticians Pay Attention To Six Sigma? Qual. Prog., 32(9), 100-103.

Tagahaboni-Dutta, F., and Moreland, K. (2004). Using six-sigma to improve loan portfolio performance. The Journal of American Academy of Business, 5 (1/2), 15-20.

Wiklund, H., \& Wiklund, P. (2002). Widening the Six Sigma concept: An approach to improve organizational learning. Total Quality Management, 13(2), 233-239.

$\mathrm{Zu}$, X., Fredendall, L.D., and Douglas, T.J. (2008). The evolving theory of quality management: the role of Six Sigma. Journal of Operations Management, 26 (5), 630-650. 


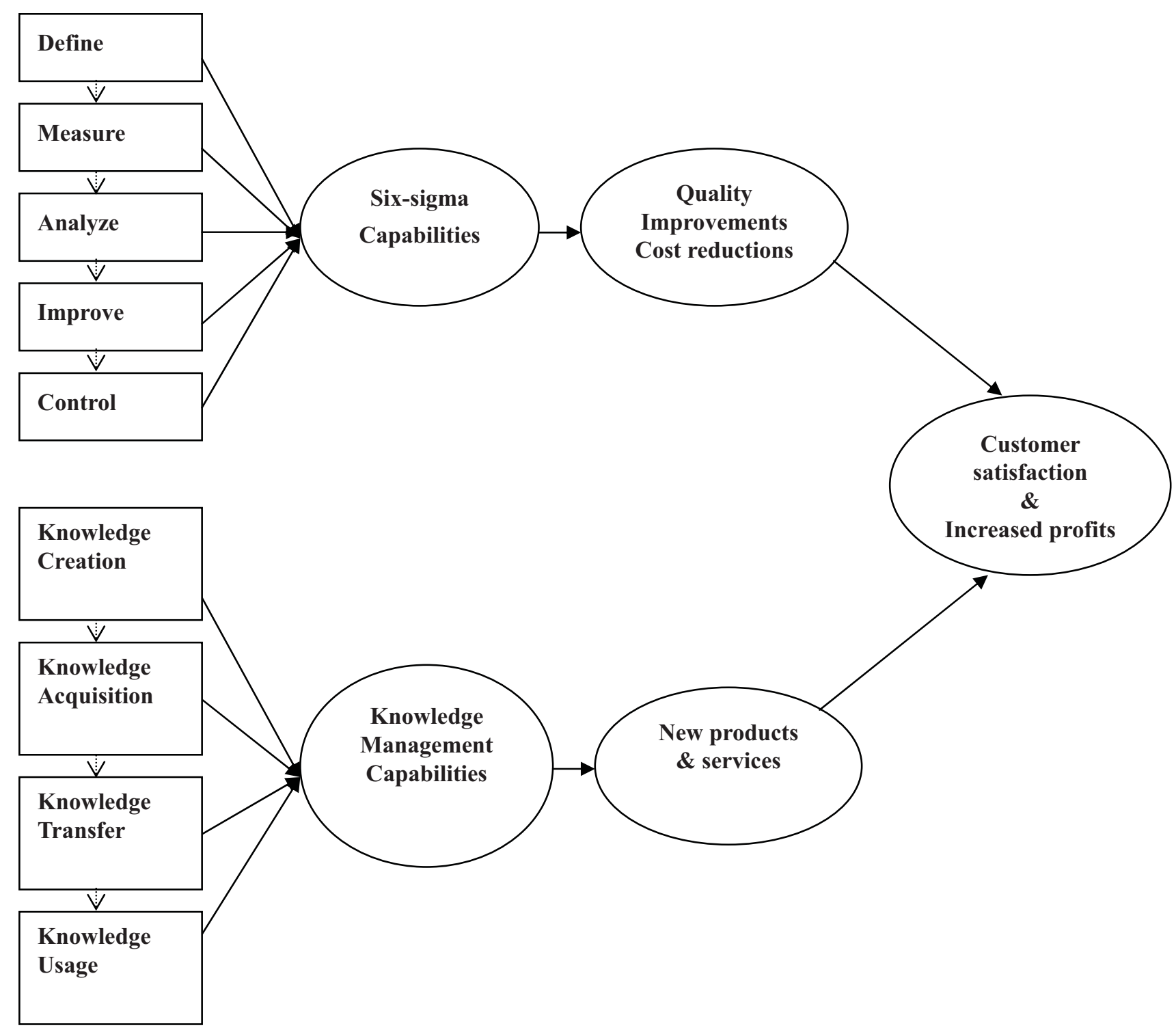

Figure 1. Six Sigma and Knowledge Management Alignment Model 